\title{
Promoção de Valores Morais e a Formação Acadêmica do Tecnólogo na área de Informática
}

\section{Promotion of Moral Values and the Academic Training of the Technologist in the area of Informat-}

\author{
LUIS EDUARDO PINHEIRO NEVES \\ Universidade Ceuma \\ GYLNARA K. F.CARVALHEDO ALMEIDA \\ Universidade Ceuma \\ DELMO MATTOS DA SILVA \\ Universidade Ceuma \\ WILL RIBAMAR MENDES ALMEIDA \\ Universidade Ceuma
}

\begin{abstract}
Resumo: Este artigo faz uma análise sobre importantes perspectivas referentes aos valores morais de responsabilidade e solidariedade a serem desenvolvidos em Instituições de Ensino Superior, focando as vertentes específicas das Universidades particulares no contexto dos cursos do eixo técnico da área de Análise e Desenvolvimento de Sistemas. Assim, visou-se analisar os fatores necessários para promoção dos valores morais dos sujeitos-alunos em relação ao contexto acadêmico e à formação profissional ampla. A amostra foi constituída por 13 estudantes, com idade entre vinte e cinco e trinta anos, acadêmicos do referido curso de uma Universidade particular em São Luís, doravante denominada Universidade ALPHA. Os resultados apontaram, conforme linhas da pesquisa de referência replicada, que, para os alunos sujeitos da pesquisa, a formação acadêmica em questão tem como principal função o acesso a bens materiais e à inserção no mercado de trabalho, sendo referido em segundo plano o desenvolvimento dos valores analisados como objetivo educacional do Ensino Superior.
\end{abstract}

Palavras-chave: Ensino Superior. Educação Tecnológica. Valores Morais.

\begin{abstract}
This article analyzes important perspectives regarding the moral values of responsibility and solidarity to be developed in Higher Education Institutions, focusing on the specific aspects of private universities in the context of the courses of the technical axis, Analysis and Development of Systems. Thus, it was aimed to analyze the factors necessary to promote the moral values of the subjects-students in relation to the academic context and the broad professional formation. The sample consisted of 13 students, aged between twenty and five and thirty years, of a private university in São Luís, henceforth denominated APLHA University. The results pointed out, according to the lines of the research of replicated reference, that for the students, subject of the research, the academic training in question has as main function the access to material goods and insertion in the labor market, being placed in the background the development of values analyzed as educational objective of Higher Education.
\end{abstract}

Keywords: Higher Education. Technological Education. Moral Values.

NEVES, Luis Eduardo Pinheiro; ALMEIDA, GyInara K. F. Carvalhedo;SILVA, Delmo Mattos da; ALMEIDA; Will Ribamar Mendes. Promoção de Valores Morais e a Formação Acadêmica do Tecnólogo na área de Informática. Informática na Educação: teoria \& prática, Porto Alegre, v. 21, n. 2, p. 138-152, mai./ago. 2018. 


\section{Introdução}

Para Valente (1989), ao professor e à escola, no seu todo, o ensino de valores não se poderá evitar, seja através de permissões e proibições, seja por valorizações ou seja, ainda por desvalorizações, por definições do que é justo ou não, naquilo que se incentiva ou não. Tal realidade é concernente a todo nível de educação formal ou informal, em qualquer nível de conhecimento básico ou superior, em Instituições públicas ou privadas, ou ainda em cursos da área de humanas ou técnica, bacharelado, licenciatura ou tecnólogos. Assim, tratar de valores é essencial para qualquer contexto, mesmo na referida sociedade informática, na qual a substituição do trabalho humano pelas máquinas poderá reforçar a necessidade do caráter conteudista e tecnicista das atividades de aprendizagem, em detrimento das questões transversais que preparariam o profissional para uma atuação ampla no desenvolvimento da sociedade. Nesta última perspectiva, entende-se que as habilidades de aprender a fazer, aprender a conhecer, aprender a conviver e aprender a ser, definidas pela UNESCO e relatadas em Delors (2003) para a Educação do século XXI, seriam mais eficazmente aplicadas.

Por outro lado, a teoria do desenvolvimento humano (PIAGET, 1932/1994) enfoca que alguns aspectos temporais específicos são observados na aquisição de valores. Cita-se, por exemplo, o condicionamento da moral à punição, presença de agente fiscalizador, em determinadas fases (heterônoma), ou ainda na fase autônoma, onde se espera que o indivíduo já reconheça as regras e leis, se comporte de acordo ou não tendo consciência de sua capacidade de propor mudanças consistentes nas mesmas. Podem-se ainda observar, nesse contexto, padrões de comportamento diferenciados dos estudantes conforme o nível da educação formal.

Assim, em relação ao desenvolvimento de valores, há de serem observados alguns fatores específicos associados a essas diversas fases, no caso desta pesquisa, acadêmicos na faixa etária de 22 a 30 anos, e contextos de tipos de formação específicas, nas quais alguns focos são priorizados, como na área de Sistemas de Informação. Quais, então, são os itens referentes a valores de responsabilidade e solidariedade que são estimulados nas relações acadêmicas na realidade de Instituições de Ensino Superior privado em contextos específicos referentes a cursos do eixo técnico da área de Sistemas de Informação? Para discutir tal problema, embasamo-nos em pesquisa similar realizada com estudantes dos $5^{\circ}$ e $6^{\circ}$ períodos da disciplina Banco de Dados, do Curso de Ciência da Computação das Faculdades Integradas Espírito-Santenses (SAMPAIO, 2004), sendo que, naquela pesquisa, além da análise dos valores morais de responsabilidade e solidariedade presentes nas relações acadêmicas, foi elaborada uma estratégia de desenvolvimento desses valores, o que não é objetivo desta pesquisa.

Da mesma forma que na pesquisa de referência, este trabalho abrange os valores de responsabilidade e da solidariedade através de indicadores específicos: consciência de suas obrigações, capacidade de tomar decisões, a segurança em si mesmo, a constância de propósito; a autoproposição de metas e a capacidade de responder por seus atos. E, em relação à solidariedade, esta é caracterizada pelos indicadores: colaboração, apoio às outras pessoas, 
compreensão a situação dos demais, comunicação afetiva, disposição às atividades compartilhadas e desprendimento (SAMPAIO, 2004).

Como professores do Ensino Superior atuantes em cursos de nível acadêmico na área de Gestão e Tecnologia da Informação com uma média treze anos, e tendo neste período visualizado empiricamente a falta de prioridade no desenvolvimento de valores morais e ainda em outras questões ditas transversais no processo cognitivo específico dessas áreas a partir de pesquisas do assunto em voga, observa-se a realidade ratificada na pesquisa em tela e, desta forma, foi identificada a necessidade de uma análise in-loco na referida Universidade, doravante denominada ALPHA, pela qual nos sentimos responsáveis enquanto educadores.

Para alcançar tal objetivo, foram selecionados, por critério de inclusão, baseado na presença dos estudantes nas aulas ministradas pelo pesquisadores, no período de levantamento de dados, 13 estudantes de um total de vinte e cinco, todos acadêmicos dos $5^{\circ}$ e $6^{\circ}$ períodos de um curso de Análise e Desenvolvimento de Sistemas daquela Universidade particular em São Luís-MA, utilizando-se de questionário baseado em questões similares à pesquisa replicada, conforme é detalhado no item Procedimentos Metodológicos.

De acordo com Cloniger (1999), há várias doutrinas em relação ao estudo da personalidade humana, entre as quais a da perspectiva de Sigmund Freud e Carl Gustav Jung, que defendem a relevância do inconsciente na conduta da pessoa (Doutrina Psicanalítica); a linha de Alfred Adler, Eric Ericson e Karen Horney, que defendem o ego como determinante desta conduta (Doutrina sócio-psicanalista).

Cloniger (1999) refere ainda as linhas de pensamento de Raymond B. Cattell e Gordon Allport que definem serem traços da personalidade mais ou menos presentes de acordo com o tempo e situação; refere-se também à percepção de Burrhus Frederic Skinner, John Dollard e Neal Miller, os quais atribuem ao comportamento o principal fator responsável pela personalidade humana (Doutrina da aprendizagem); A doutrina de Walter Mischel, Albert Bandura e George Kelly, os quais defendem que, para conhecer-se a personalidade da pessoa, é importante saber o que elas pensam (teoria da aprendizagem cognitiva social); e, por fim, a teoria de Carl Rogers e Abraham Maslow que valoriza a experiência subjetiva do indivíduo, onde o presente é mais importante do que o passado (linha Humanista).

Por outro lado, González-Rey (1989) destaca a integração entre os aspectos cognitivos e afetivos como importantes para a formação da personalidade, compactuando com o pensamento de Vigotski, quando define as emoções como fator essencial para essa formação. Nesta última perspectiva é que será abordada essa pesquisa, baseada assim na interdisciplinaridade entre os aspectos cognitivos e afetivos como fator determinante para a formação da personalidade dos discentes envolvidos através da construção de valores morais, como parte importante da vida plena dos indivíduos, pois, segundo Arteaga (1999), é a concepção sobre esses valores que orienta a atuação social.

As seções deste trabalho estão dispostas de tal forma que, inicialmente, discute-se o amplo papel do docente na formação dos alunos do ensino superior, o qual é então relacionado na segunda seção aos valores especificos de responsabilidade e solidariedade, uma vez que esses aspectos são diretamente associados à pesquisa de campo. Abordam-se ainda os fatores que 
influenciam a formação acadêmica de cursos específicos da área de Tecnologia da Informação. Após, serão apresentados os procedimentos metodológicos e, finalmente, a apresentação, análise e discussão dos resultados da pesquisa em campo.

\title{
2 A influência dos docentes na formação de valores nos estudantes do Ensino Superior
}

Considera-se que reside nas mãos do professor universitário a responsabilidade de formar todos os outros profissionais, que deverão atuar de forma a atender aos anseios em várias vertentes da sociedade, tanto no que diz respeito à sua capacidade técnica, quanto também em relação à postura ética para com a sociedade. Questiona-se, então, o quanto esses educadores foram preparados para exercer esse papel. A saber:

\begin{abstract}
Verificou-se a influência do docente no ensino superior, na formação ética do aluno, demonstrada através de reflexões sobre a relação professor aluno, pelo papel político do docente na sociedade e do exemplo que este representa para os alunos. Dentre as observações feitas destaca-se, pela importância, a maneira que o docente deve proceder em sua prática pedagógica e na inter-relação com o aluno, uma vez que ele representa na sala de aula uma imagem concreta da Universidade. (ROCHA, 2006, pág. 1).
\end{abstract}

A postura do professor universitário que se restringe a apenas deter conhecimentos técnicos referentes à sua disciplina não condiz com seu papel de formador da Universidade, enquanto espaço de transformação holística. O educador, em sua essência em qualquer nível, é tido como referencial para os seus alunos; portanto, é de fundamental importância que o docente se perceba como agente ativo na formação dos alunos sob sua responsabilidade.

Para Kant (1996), a Educação tem a função de transformar o ser humano em ser humano: "O homem não pode tornar-se um verdadeiro homem senão pela educação. Ele é aquilo que a educação dele faz" (KANT, 1996, p. 15). Por outro lado, a desintegração de objetivos da Gestão Pedagógica da própria Universidade às vezes não privilegia a posição de Kant, nos vários estágios do processo de construção do conhecimento, baseado em necessidades mercantilistas, pois, orienta então o professor a ter uma postura tecnicista e conteudista. Nalini (1999) corrobora a tese, afirmando que "os docentes têm um grande número de alunos, e um tempo muito reduzido para lidar com eles". Isso os impede de realizar um trabalho com maior proximidade com seus discípulos.

Veiga et al. (2002), em Pedagogia Universitária, defendem a ideia de que:

A relação aluno-docente, se dialógica, pode ser uma alavanca na produção do conhecimento e aposta na convivência acadêmica entre os alunos da graduação e da pós-graduação como um ponto facilitador no contato com a pesquisa, na troca de experiências e na abertura de perspectiva mútua. Se, por um lado, valoriza os conteúdos da área, entende como fundamentais as atitudes de respeito ao aluno, enfatizando as formas significativas de mediações interpessoais. 
Assim, uma formação mais ampla requer que todos os agentes estejam envolvidos nesta postura, de tal forma que, desde o planejamento até a avaliação esteja, ainda que de forma transversal, voltada para a construção de valores amplos e não apenas dirigidos para a formação profissional técnica.

Deve-se estimular uma relação afetiva com os discentes por meio de valores como a exemplo da cordialidade, estima, do respeito às diferenças; e, através desta relação, acredita-se que os contextos técnicos mais específicos podem ser discutidos e sempre retomados para questões associadas a valores de responsabilidade e solidariedade na tomada de decisões de caráter mais técnico, sem prejudicar a competitividade que nos é solicitada pela sociedade moderna. Diante disso, Goergen (2001) afirma que uma das funções da escola, nos dias de hoje, é compreender e influenciar a formação dos estudantes nos ambientes educacionais a fim de se estimular uma concepção para a vida, com uma nova consciência.

Ainda, conforme afirmativa de Rios (1997):

É preciso pensar que o educador ético e competente é um educador comprometido com a construção de uma sociedade justa, democrática, na qual saber e poder tenham equivalência enquanto elementos de interferência no real e na organização de relações de solidariedade, e não de dominação entre os homens. Uma visão clara, abrangente e profunda do papel que desempenha na sociedade permite ao educador uma atuação mais completa e coerente. A atitude crítica do docente sobre os meios e os fins de sua atuação o ajudará a caminhar mais seguramente na direção de seus objetivos.

Enfatiza-se que é essencial o domínio do conteúdo referente ao escopo da disciplina que o professor ministra, entretanto também se faz necessário o comprometimento com os valores morais, uma vez que, é de suma importancia contextualizar o currículo de forma transdisciplinar, integrando o conhecimento científico a padrões de comportamento coerente. Deste modo, a contribuição dos professores no Ensino Superior, caso seja baseada de fato no fazer pedagógico, através de atitudes e exemplos contextualizados de forma transdisciplinar, não servirá só para preparar os jovens ou não só para encarar as posições profissionais que os esperam, mas para fazê-lo de forma a integrá-los na vida social plena, de forma ativa e transformadora segundo padrões de comportamento aceitáveis.

\section{Responsabilidade e solidariedade como valores na formação acadêmica}

O estudo da problemática dos valores, denominado de Axiologia, termo derivado do grego "axia" e que significa "valor", aponta para o pensamento de Kant (1996), que defende ser valor o dever ser de uma norma (que pode não ter realização prática), mas que atribui verdade, bondade e beleza às coisas julgáveis. Segundo esta taxonomia, existem quatro tipos de valor: os verdadeiros, os materiais, os estéticos e os morais. Os valores verdadeiros são as ideias e princípios importantes que adotamos como nossos, e que dão sentido à vida. Os valores materiais são o dinheiro, objetos dos mais variados e a beleza física. Os valores estéticos são a música preferida, poesias, pinturas. E, finalmente, os valores morais são a justiça, honestidade, verdade, respeito, responsabilidade, solidariedade, entre outros. Os valores morais, foco desta 
pesquisa, segundo Souza (2005), são aqueles que se baseiam na honra e dignidade do sujeito, ligados ao senso de justiça, honestidade, generosidade e lealdade.

Comte-Sponville (1999) faz um estudo detalhado dos vários tipos de valores, o qual cita a generosidade como uma motivação do agir para o bem, desvinculando-o do interesse, pois, segundo esse autor, só poderemos ser generosos sem querer possuir o que é do outro. A solidariedade tratada neste trabalho é concebida como uma vertente da generosidade. Há que se ressaltar que a solidariedade deverá ser exercida sem entra em uma seara que possa ser confundida com assistencialismos desregrados.

Dentre os valores que envolvem a formação moral, dedicamos este trabalho ao estudo da responsabilidade e da solidariedade. Para melhor conhecer como se formam esses valores, assim como a pesquisa replicada, partimos dos indicadores apontados abaixo, os quais representam, de maneira mais explícita, a necessidade pragmática dos mesmos no âmbito do campo da pesquisa.

1. Consciência de suas obrigações; Capacidade de tomar decisões; Segurança em si mesmo; Constância de propósito; Autoproposição de metas; Capacidade de responder por seus atos.

Já a solidariedade é aqui caracterizada pelos indicadores:

2. Colaboração; Apoio às outras pessoas; Compreensão a situação dos demais; Comunicação afetiva; Disposição às atividades compartilhadas; Desprendimento.

\section{Formação de valores em cursos na área de sistemas de informação}

As Diretrizes Curriculares para os Cursos de Computação (2012) e as indicações de currículos para cursos da área de Sistemas e Tecnologias da Informação, editadas pela Sociedade Brasileira de Computação (2012), sinalizam eixos de disciplinas para formação humanística, tais como a Ética, Sociologia, Filosofia, as quais nas Universidades se apresentam sob várias terminologias, como Sociedade da Informação e Ética, Ética aplicada à Computação, Introdução à Filosofia, ou mesmo como unidades contextualizadas em disciplina de cunho mais genérico. Os desenvolvimentos de tais conteúdos se deparam com duas situações, em que estão associadas ao perfil dos profissionais da Educação, que são alocados para atuarem como docentes dessas disciplinas.

Sampaio (2004, p. 5) diz que:

Outro aspecto é que, em geral, a responsabilidade sobre a formação humanística, e neste caso a moral, recai sobre as disciplinas humanas. Reconhecemos que uma parcela significativa de responsabilidade seja dessas disciplinas, porém, destacamos esta formação como sendo interdisciplinar e transversal dentro do currículo da computação. 
Algumas vezes convivemos com profissionais técnicos, que, sem embasamento teórico, focam aspectos práticos por meio de estudos de caso que sinalizam padrão de comportamento baseado nos valores morais eminentemente de forma empírica. Por outro lado, há uma profundidade teórica, porém, falta contextualização associada à área específica, como é o caso do curso de Desenvolvimento de Sistemas, abrindo um vácuo entre a teoria e a prática. Observase empiricamente que grande parte daqueles que conseguem ter algum tratamento interdisciplinar do tema, referem-se às questões meramente tecnicistas como as associadas à invasão de privacidade e a quebra de segurança dos dados, deixando a desejar em questões da formação humanística integral, frente à pessoa e seus valores.

A sociedade da Informação, capitaneada pelo ciberespaço da Internet, bem como suas mazelas sociais, realmente abrem vertentes transdisciplinares a serem desenvolvidas, no que diz respeito a padrões de comportamento moral. Direcionar um padrão de comportamento em um ambiente digital aberto é tão complexo como os de outras mídias que usam outras tecnologias da Informação e comunicação. Nesse contexto, cabe a nós, educadores inseridos no processo de Educação mediada por Tecnologia usarmos continuamente formas de comunicação contextualizadas ao ambiente hipertextual da Internet, para passarmos valores de convivência online, sem se submeter a estes.

Como abordado em Dias e Medeiros (2016), o aumento dos meios de aprendizagem, por meio de sistemas computacionais associados à não formação cultural no que diz respeito a valores morais, estimula ações como espalhar vírus de computador, enviar por e-mail a amigos as respostas de questões de exames universitários, ver pornografia, e enviar mensagens sexualmente explícitas a estranhos e o próprio cyberbullying, o que serve de base para a constatação da necessidade do desenvolvimento de consciências educacionais específicas para aqueles ambientes virtuais, a serem desenvolvidas dentro e fora do ensino superior.

\section{Procedimentos Metodológicos}

Este trabalho está compreendido na abordagem quantitativa de pesquisa, e visou diagnosticar e quantificar as questões relacionadas aos valores morais tratados no contexto da realidade acadêmica em questão. Tal diagnóstico foi realizado em uma Universidade particular em São Luís - MA, junto a 13 estudantes com idade compreendida entre 22 a 30 anos matriculados nos últimos períodos (quarto e quinto) do curso de Análise e Desenvolvimento de Sistemas da Instituição ALPHA. O curso em questão é formatado em 5 períodos, tendo cerca de cem alunos com vinte e cinco nos períodos foco da pesquisa, configurando, desta forma, representatividade em relação ao universo geral.

A amostra foi não probabilística, intencional, baseada no critério de participação dos discentes dos últimos períodos do curso $\left(4^{\circ}\right.$ e $\left.5^{\circ}\right)$ nas aulas ministradas pelos pesquisadores durante 0 período do levantamento de dados. Tal critério de seleção está associado ao fato de já estarem no fim do curso e tido, então, envolvimento com boa parte do processo de aprendizagem formal do mesmo. A aplicação do processo ocorreu no ambiente de sala de aula, mais precisamente no 
término das mesmas, após explicação dos objetivos da pesquisa. Ressalte-se o perfil profissional que os participantes possuem, uma vez que $90 \%$ deles já são trabalhadores atuantes na área profissional do curso.

A aplicação da pesquisa no trabalho de referência replicada verificou-se, em linhas gerais, em duas etapas, uma a qual os autores chamaram de diagnóstico, cujo objetivo foi a avaliação da situação do desenvolvimento moral dos alunos; e a outra que tivesse como objetivo planejar e aplicar ações específicas para desenvolvimento dos valores identificados como frágeis. Essa pesquisa se limitou à fase de diagnóstico, obtido a partir da aplicação de questionários objetivos fechados processados matematicamente e mediante cálculo percentual simples com o intuito de identificar de que forma os indicadores de responsabilidade e solidariedade estiveram presentes nas ações educativas do referido curso da Universidade particular ALPHA.

A Universidade em questão atua há cerca de vinte e cinco anos em cinco campi, com cursos superiores de várias áreas de conhecimento, nas modalidades presenciais e a distância em cursos de Licenciatura, Bacharelado e Tecnólogo, tendo cerca de vinte mil alunos egressos, desde a sua fundação. A aplicação do instrumento de pesquisa, ou seja, dos questionários, foi realizada durante uma semana e ocorreu no mês de agosto de 2015, pelos próprios pesquisadores. Antes da distribuição do questionário em sala de aula foram explicados os objetivos e metodologias, bem como os conceitos básicos dos valores responsabilidade e solidariedade, assim como seus indicadores, sendo recolhida prontamente tal ferramenta respondida. Foi garantida a possibilidade de não participação dos mesmos, assim como também a garantia de sigilo das informações prestadas.

Figura1 - Itens indicadores aplicados no questionário de pesquisa.

REPONSABILIDADE
\begin{tabular}{|l|l|l|l|l|l|}
\hline & Desistimulado & $\begin{array}{c}\text { Nunca } \\
\text { estimulado }\end{array}$ & $\begin{array}{c}\text { Estimulado } \\
\text { superficialmente }\end{array}$ & $\begin{array}{c}\text { Muito } \\
\text { estimulado }\end{array}$ & $\begin{array}{c}\text { Estimulado } \\
\text { exageradamente }\end{array}$ \\
\hline $\begin{array}{l}\text { Consciência de } \\
\text { suas obrigações }\end{array}$ & & & & & \\
\hline $\begin{array}{l}\text { Segurança em si } \\
\text { mesmo }\end{array}$ & & & & & \\
\hline Tomada de decisão & & & & & \\
\hline $\begin{array}{l}\text { Constância de } \\
\text { propósito }\end{array}$ & & & & & \\
\hline $\begin{array}{l}\text { Responder por } \\
\text { seus atos }\end{array}$ & & & & & \\
\hline
\end{tabular}

\begin{tabular}{|l|l|l|l|l|l|}
\hline \multicolumn{2}{|l|}{ SOLIDARIEDADE } & \multicolumn{1}{l|}{} & \\
\hline Colaboração & & & & & \\
\hline $\begin{array}{l}\text { Sensibilidade } \\
\text { Humana }\end{array}$ & & & & & \\
\hline $\begin{array}{l}\text { Comunicação } \\
\text { af etiva }\end{array}$ & & & & & \\
\hline $\begin{array}{l}\text { Disposição á ações } \\
\text { compartilhadas }\end{array}$ & & & & & \\
\hline Desprendimento & & & & & \\
\hline
\end{tabular}

Fonte: Dados levantados do questionário de pesquisa

O questionário foi objetivo, sendo usadas perguntas fechadas, conforme a Figura 1, baseando-se nos indicadores citados na seção 3 deste trabalho. A pergunta geral, tanto em 
relação aos conceitos de responsabilidade quanto em relação à solidariedade, foi: "Durante o seu curso de Análise de Desenvolvimento de Sistemas, nesta Instituição, de que forma os valores abaixo especificados foram tratados pelos professores, de forma direta ou indireta nas atividades curriculares internas ou externas?, sendo reforçada pela questão explicativa se "Em algum momento das disciplinas tais valores foram estimulados pelos professores por meio de suas atividades em sala de aula ou através de trabalhos?". Foi então solicitado que, para cada subcritério, o discente marcasse a alternativa que mais se adequasse ao nível de atenção dada a cada um dos indicadores durante o percurso do curso.

Ressalte-se o caráter de subjetividade não meramente quantitativa em relação às métricas de caracterização do nível de estimulação de cada valor, de tal forma que, quando o aluno da amostra indicava ter sido "estimulado", "estimulado parcialmente", "muito estimulado", ou "estimulado exageradamente", tais níveis de fato tiveram um caráter de individualidade valorativa, o que por si só já indicam métricas que estão associadas a variáveis que envolvem a percepção pessoal não quantitativa, uma vez que a pesquisa, apesar de ter tido uma abordagem quantitativa, teve teor de análise qualitativo, baseado nessas percepções.

\section{Apresentação, análise e discussão dos dados}

Em relação à análise e aos resultados, por se tratar de uma pesquisa envolvendo análise quantitativa de dados, apresenta-se a seguir uma compilação dos resultados por valor moral e indicador. Tal análise foi realizada em categoria única em relação à amostra pesquisada, a saber, todos os 13 estudantes pesquisados, analisados conjuntamente. Foi feita, então, a tabulação e distribuição de frequências usando-se tabelas para verificar as relações que apresentam entre si, e a apresentação dos dados sob a forma de frequências relativas (\%) via gráficos. Como medida de posição central, valor mais frequente de uma distribuição, foi usada a moda.

Gráfico 1 - Tabulação dos dados referentes ao indicador Responsabilidade.

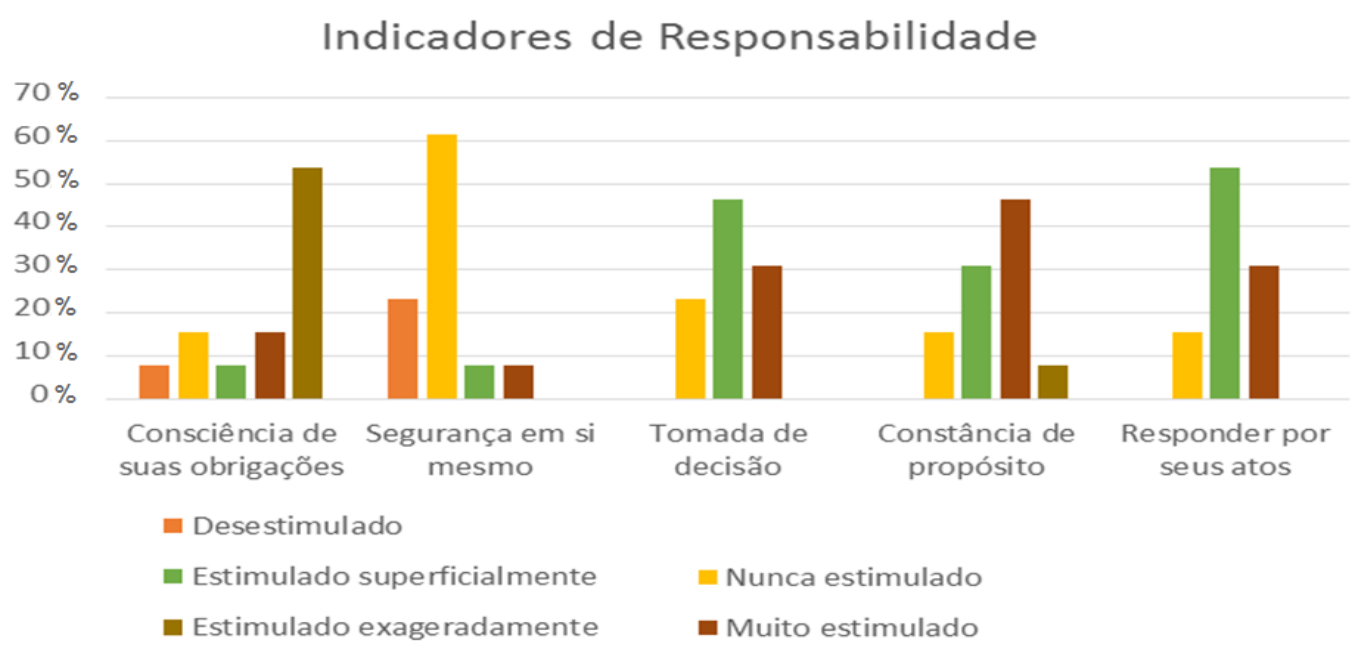

Fonte: Dados levantados através de questionário de pesquisa 
Em relação às métricas de Responsabilidade, observa-se, conforme o Gráfico 1, que, em relação ao indicador consciência com suas obrigações, cerca de 7,7 \% (1 aluno) se sentiram desestimulados, 7,7 \% (1 aluno), também, estimulados superficialmente (menor frequência), $15 \%$ ( 2 alunos), nunca estimulados e outros 15\% (2) estimulados exageradamente. Como maior frequência, verificou-se o indicador estimulado exageradamente com cerca de 54\% (7 alunos) dos entrevistados.

Em relação ao indicador Segurança em si mesmo, cerca de $23 \%$ (3 alunos) se sentiram estimulados; 7,7\% ( 1 aluno) consideraram-se estimulados superficialmente e outros 7,7 \% (1 aluno) se sentiram muito estimulados. Nenhum aluno se sentiu estimulado exageradamente (menor frequência). Como maior frequência, observou-se a métrica nunca estimulado, com cerca de $61,5 \%$ (8 alunos).

Em relação ao indicador Tomada de decisão nenhum aluno se sentiu desestimulado (menor frequência) $23 \%$ ( 3 alunos) relataram nunca terem sido estimulados, 30,1\% (4 alunos) muito estimulado e, como maior frequência, foi relatado o estímulo superficial, com cerca de 46,2 \% (6 alunos).

Como maior frequência no indicador Constância de propósito foram identificados aqueles alunos que se sentiram muito estimulados com 46,2\% ( 6 alunos), e a menor frequência dos desestimulados, sem nenhuma percentagem. Ainda neste indicador, tivemos os nunca estimulados com 15,3\% (2 alunos) e os que se sentiram estimulados superficialmente, com cerca de $30,1 \%$ ( 4 alunos) e estimulados exageradamente, com cerca de $7,7 \%$ ( 1 alunos) dos entrevistados.

Em relação ao indicador Resposta por seus atos, perto de 53,9\% ( 7 alunos) se sentiram estimulados superficialmente, a qual foi identificada como frequência majoritária. Nenhum aluno se sentiu desestimulado; 30,1\% (4 alunos) sentiram-se muito estimulados e 15,4\% ( 2 alunos) nunca estimulados.

Gráfico 2 - Tabulação dos dados levantados na pesquisa referente ao indicador Solidariedade.

\section{Indicadores de Solidariedade}

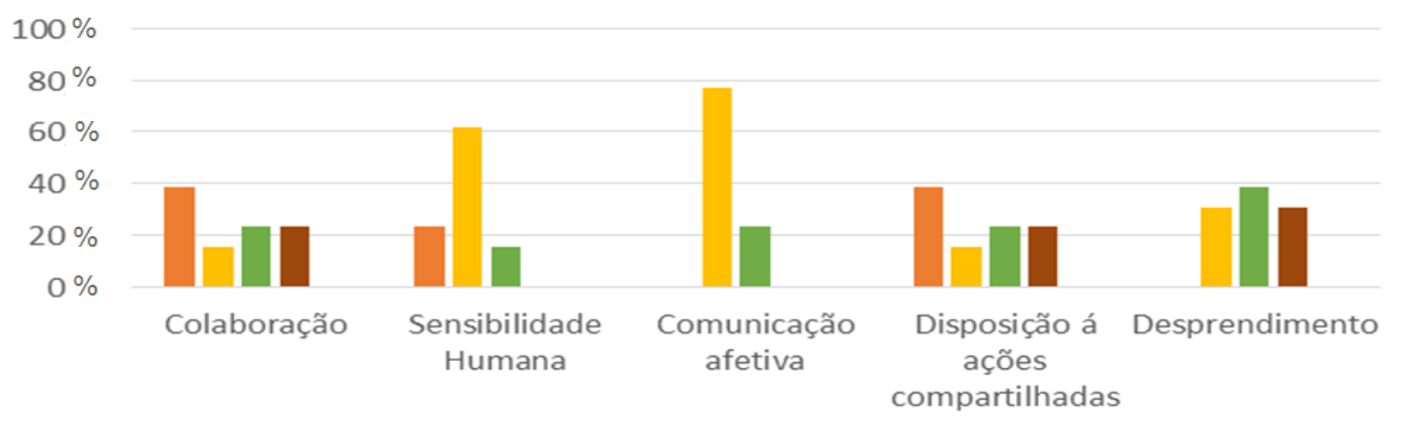

- Desestimulado

- Estimulado superficialmente

- Nunca estimulado

- Estimulado exageradamente

- Muito estimulado

Fonte: Dados levantados através de questionário de pesquisa 
Em relação aos indicadores de Solidariedade, conforme o Gráfico 2, foram observadas as seguintes métricas: $38,5 \%$ ( 5 alunos) dos alunos indicaram ser desestimulados na colaboração com os colegas, sendo este indicador preponderante; 23,1\% (3 alunos) se sentiram estimulados parcialmente ou muito estimulados, e a minoria indicou nunca ter sido estimulada para tal colaboração. O indicador Sensibilidade humana apontou para a maioria como nunca ter sido estimulada (61,5\%), ou seja, 8 alunos; nenhum aluno indicou ter sido muito ou exageradamente estimulado; Cerca de 23,1\% (3 alunos) indicaram ser desestimulados e 15,3\% (2 alunos) estimulados superficialmente.

Em relação à Comunicação afetiva, segundo os sujeitos da pesquisa, foi preponderante o sentimento de nunca terem sido estimulados, com a maioria absoluta de 76,1\% (10 alunos) dando esta indicação, e apenas 23\% (3 alunos) indicaram serem estimulados superficialmente e nenhum aluno tendo indicado como estimulado ou a métrica superior. Enfatiza-se o desestímulo a ações compartilhadas como item mais sinalizado, com cerca de 39\% (5 alunos), dando esta indicação e cerca de 23,1\% (3 alunos) indicou o estímulo de alguma forma.

Por fim, registre-se o Estímulo superficial ao desprendimento como item majoritário neste indicador, havendo um certo equilíbrio entre o Nunca e o Muito estimulado com 30,1\% (4 alunos) dos registros e nenhuma indicação de Desestímulo ou Estímulo exagerado neste item.

Em uma análise geral, pode-se, então, observar que os alunos sujeitos da pesquisa sentiramse preponderantemente apenas estimulados superficialmente ou nunca estimulados nos aspectos referentes à Responsabilidade, já que um total de $55 \%$ das indicações foram para esta métrica. Enfatize-se o indicador Segurança em si mesmo com $61 \%$ das indicações como nunca terem sido estimulados.

Nesta mesma análise, em relação ao valor Solidariedade, também foi observada esta perspectiva, ou seja: cerca de $64 \%$ também se sentiram ou estimulados superficialmente ou nunca estimulados. Enfatize-se o valor Comunicação afetiva com 76\%, tendo indicado nunca terem sido estimulados. Assim colheram-se cerca de $60 \%$ dos alunos-sujeitos da pesquisa se sentindo ou nunca estimulados ou estimulados superficialmente nos dois valores analisados.

Em uma análise mais qualitativa e subjetiva, baseada na experiência dos autores com os sujeitos da pesquisa, podem-se atribuir alguns fatores específicos aos resultados: o estímulo exagerado, indicado como fator preponderante para o item Consciência de suas obrigações, pode estar na característica tecnológica do curso e, em função disso, várias atividades sempre foram solicitadas e enfatizados os prazos e responsabilidades individuais de cada grupo ou membro (Responsabilidade); O perfil profissional dos acadêmicos, uma vez que a maioria já é profissional da área, associada então à necessidade de uma relação formal, pragmática e mecanicista por parte dos atores do processo educacional, pode ser um fator real de não afetividade e sensibilidade humana apresentada na pesquisa (Solidariedade).

Desta forma, sem querer generalizar, uma vez que se trata de um estudo de caso, observase que o tratamento do processo educacional de forma integrada e transdisciplinar associando os conceitos específicos técnicos de cada área com os valores morais, é necessário ser bem mais estimulado para a preparação ampla do estudante desta área de conhecimento, pois esta 
integração de valores contribuirá para a preparação do profissional para atuar adequadamente na sua profissão, na vida e na sociedade.

A percepção de que tal integração de valores nem sempre é desenvolvida nos cursos da área de Informática é um primeiro passo para o desenvolvimento de mudanças nos parâmetros curriculares estabelecidos pelo Ministério da Educação e pela própria Sociedade Brasileira de Computação, e, caso contrário, tal limitação perpetuar-se-á, já que as próximas gerações continuarão esse processo enquanto educadores meramente tecnicistas.

\section{Considerações finais}

É essencial que, a partir desta análise inicial, estabeleçamos estratégias didáticas para alunos e professores de tal forma que se possa reverter tal situação e, então, desenvolver-se objetivamente valores morais em estudantes dessa área de conhecimento. A hipótese inicial de que haveria uma preocupação limitada com os temas transversais, que desenvolvam valores morais de responsabilidade e solidariedade no ambiente acadêmico de graduação do curso Tecnológico em Informática pesquisado, foi confirmada.

A educação de valores é uma exigência da sociedade atual inserida no mundo globalizado. A moralidade está relacionada à ação do sujeito, ou seja: aos atos que os indivíduos praticam a partir de relações interpessoais e com o meio em que vivem, contudo, a moralidade não se resume aos atos. Segundo Piaget (1978), o desenvolvimento do juízo moral se relaciona à ação, mas não de maneira direta, ou seja: os juízos morais encaminham ações morais de modo possível. A construção de valores morais pode dar-se no decorrer das vivências, passando por um processo sucessivo, o qual acontece na interação do indivíduo com o meio cultural e social e mediante relações interpessoais. Neste sentido, o papel do professor é de fundamental importância, uma vez que ele é responsável por promover e estimular o respeito mútuo advindo das relações de cooperação, que têm como propósito a autonomia.

Assim, observou-se que, no caso pesquisado, a formação acadêmica em questão tem como principal função o acesso a bens materiais e à inserção no mercado de trabalho, sendo colocado em segundo plano o desenvolvimento dos valores analisados como objetivo educacional do Ensino Superior. Foi identificado dessa forma que é o momento de serem repensadas estratégias educacionais aplicadas no campo estudado, agregando às mesmas dinâmicas que integram os assuntos técnicos como programação e gerenciamento de informações às atividades que estimulem os valores morais aqui apresentados.

No âmbito da Educação, há uma preocupação das instituições sobre a relação da hierarquização de identidades como fator principal da hegemonia de uma determinada identidade sobre as demais, ocasionando a exclusão de diversas singularidades. $O$ ponto de partida da reflexão desse processo na Educação se faz pela compreensão da inclusão e da observação das diversidades da inclusão e da observação das diversidades as quais impelem novas demandas para a escola e seus profissionais. Ao relacionar-se com o múltiplo, o diverso e o plural, face ao multiculturalismo, a escola se reinventa, adaptando-se na busca por 
compreender as identidades plurais, procurando questionar o trabalho que, comumente, vem realizando, de homogeneização de ritmos e estratégias, independentemente da origem social, cultural, da idade e das experiências vividas pela própria comunidade escolar.

$\mathrm{Na}$ perspectiva de Hall (1996), no que concerne ao reconhecimento da diversidade cultural percebe-se que o critério do respeito deva ser compreendido como a valorização de cada indivíduo em sua particularidade. Trata-se, portanto, de uma atitude carregada de sentimentos que podem ser confundidos de formas diferentes, como de submissão, medo, inferioridade ou podem estar associados à veneração ou consideração. Esta deve deixar de ser apenas uma atitude baseada nas empatias das relações pessoais para tornar-se um princípio que norteie todas as condutas dos indivíduos. Por sua vez, exerça-se o princípio de que todas as pessoas devem ser respeitadas independentes de sua origem social, etnia, sexo, religião e opinião, assim como as manifestações sociais e culturais dos diferentes grupos que constituem a sociedade, deste modo fundamenta-se a respeito.

Tal confirmação do caso real na Universidade ALPHA poderá servir de base para um estudo mais aprofundado, o qual poderá resultar na concepção de estratégias pedagógicas práticas, assim como sua aplicação no processo de análise, para verificação das possíveis mudanças dos valores morais estudados; e porque não outros valores de mesma categoria?

Dessa maneira, ratifica-se que os valores de responsabilidade e solidariedade nas vertentes pesquisadas não se apresentaram como uma preocupação da formação técnica daquela Universidade/Curso, na qual apenas ações isoladas de professores auxiliam o desenvolvimento desses valores, principalmente no que diz respeito à consciência de suas obrigações e disposição às atividades compartilhadas.

\section{Referências}

ARTEAGA, N. L. C. Formación de Valores Morales. La Habana: Editorial Academia, 1999.

CLONINGER, S. C. Teorias da Personalidade. São Paulo: Martins Fontes, 1999.

CONTE-SPONVILLE, André.Pequeno Tratado das Grandes Virtudes. Tradução de Eduardo Brandão.São Paulo: Martins Fontes, 1999

DELORS, J. Educação: um tesouro a descobrir. 2ed. São Paulo: Cortez Brasília, DF: MEC/UNESCO,2003.

DIAS, Mônica Soares; MEDEIROS, Lucilene G.S. Da moralidade à patologia: Como a pornografia virtual age no cérebro humano? Faculdades Integradas de Patos, 2016, p. 04. Disponível em:

<http://fiponline.edu.br/coopex/pdf/cliente=3-a952712a028753f8ba7f2d63c77ea811.pdf>

DIRETRIZES CURRICULARES DE CURSOS DA ÁREA DE COMPUTAÇÃO E INFORMÁTICA. Disponível em: http://www.mec.gov.br/sesu/diretriz.shtm Acesso em 03 dez 2015.

GOERGEN, P. (2001). Educação Moral: adestramento ou reflexão comunicativa? Educação e Sociedade, 22(76), 147-174.

GONZÁLEZ-REY, F. L.; MARTÍNEZ, A. F. La personalidad: su educación y desarrollo. La Habana: Pueblo y Educación, 1989. 
HALL, Stuart. A questão da Identidade Cultural. Trad. Guacira L. Louro e Tomaz T. da Silva. Porto Alegre: Faculdade de Educação/UFRGS, 1996.

KANT, I. Sobre a Pedagogia. Tradução de Francisco CockFontanella. Piracicaba: Editora Unimep, 1996.

NALINI, J. R. Ética geral e profissional. 2 ed. São Paulo: RT Didáticos,1999.

PIAGET, J. Para onde vai a educação? Rio de Janeiro: Unesco, 1978.

O juízo moral na criança. São Paulo: Summus, 1994. (Originalmente publicado em 1932).

ROCHA, C. B. Ética na Docência do Ensino Superior. Montes Claros - MG. Dissertação de Mestrado, 2006

RIOS, Terezinha Azerêdo. Ética e competência. 6 ed. São Paulo: Cortez,1997. (Coleção questões de nossa época).

SAMPAIO, E. C. La formación de valores morales (responsabilidad y solidaridad) atraves de la asignatura banco de datos en el curso de computación. Dissertação de Mestrado. IPLAC - 2004.

SAMPAIO, Eliana Caus ; VÁZQUEZ, Jose Manuel Perdomo . Formação de Valores Morais no Contexto da Computação. Anais da IV Escola Regional de InformaticaRj Es, Rio de Janeiro/Espirito Santo, 2004.

SOUZA, V. L. T. (2005). Escola e construção de valores. São Paulo: Loyola.

VALENTE, M. O. (1989). A Educação para os Valores. In O Ensino Básico em Portugal, pp. 133-172. ASA: Porto.

VEIGA, I. P. A. Formação de Professores: Políticas e Debates. São Paulo: Papirus, 2002.

Recebido em junho de 2018

Aprovado para publicação em julho de 2018

\section{Luis Eduardo Pinheiro Neves}

Universidade Ceuma, luiseduardoneves@yahoo.com.br

Gylnara KyIma Feitosa Carvalhedo Almeida

Universidade Ceuma, gylnara@gmail.com

Delmo Mattos da Silva

Universidade Ceuma, delmomattos@hotmail.com

Will Ribamar Mendes Almeida

Universidade Ceuma, will75@gmail.com 